The University of Maine

\title{
DigitalCommons@UMaine
}

Marine Sciences Faculty Scholarship

School of Marine Sciences

$1-1-1977$

\section{Responses of Atlantic Salmon Parr to Output of Pulsed Ultrasonic Transmitters}

D. E. Facey

James McCleave

University of Maine - Main, mccleave@maine.edu

G. E. Doyon

Follow this and additional works at: https://digitalcommons.library.umaine.edu/sms_facpub

\section{Repository Citation}

Facey, D. E.; McCleave, James; and Doyon, G. E., "Responses of Atlantic Salmon Parr to Output of Pulsed Ultrasonic Transmitters" (1977). Marine Sciences Faculty Scholarship. 107.

https://digitalcommons.library.umaine.edu/sms_facpub/107

This Article is brought to you for free and open access by DigitalCommons@UMaine. It has been accepted for inclusion in Marine Sciences Faculty Scholarship by an authorized administrator of DigitalCommons@UMaine. For more information, please contact um.library.technical.services@maine.edu. 


\title{
Responses of Atlantic Salmon Parr to Output of Pulsed Ultrasonic Transmitters
}

\author{
Douglas E. Facey, ${ }^{1}$ James D. McCleave, ${ }^{2}$ and Glen E. Doyon \\ Migratory Fish Research Institute and Department of Zoology \\ University of Maine, Orono, Maine 04473
}

\begin{abstract}
The output from some pulsed ultrasonic transmitters commonly used in fish movement studies is faintly audible to humans. This study was undertaken to determine if the output from these and some other transmitters is detectable by Atlantic salmon (Salmo salar) parr. Classical conditioning of cardiac deceleration was attempted using the transmitter's output as the conditioned stimulus. The results from 29 experimental and 14 control fish suggest that the parr were unable to detect the output from these transmitters.
\end{abstract}

The introduction of ultrasonic telemetry by Johnson (1963) and Trefethen (1956) provided a new technique to study fish movements. This method has gained widespread use in homing and migration studies (e.g. Dodson et al. 1972; Madison et al. 1972; McCleave and LaBar 1972; Stasko et al. 1973), and considerable technological improvement has been made (e.g. Ferrel et al. 1973; Greer Walker et al. 1971; Henderson et al. 1966; Luke et al. 1973). Little emphasis has been placed upon determining whether or not these transmitters affect physiological, behavioral, or locomotory processes of the fishes involved. Such effects would raise questions as to the reliability of transmitter-equipped individuals as representatives of a natural population. The effects of telemetric transmitters on the stamina of Atlantic salmon (Salmo salar) smolts were studied by McCleave and Stred (1975). Buoyancy compensation due to the added weight of a transmitter has been researched in the physoclistous bluegill (Lepomis macrochirus) (Gallepp and Magnuson 1972) and in physostomous Atlantic salmon smolts (Fried et al. 1976).

The general assumption among users of telemetry has been that ultrasonic transmitters are not audible to fishes. Tavolga (1971) stated that the upper limit of hearing in fishes is usually less than $5 \mathrm{kHz}$, and most ultrasonic transmitters operate at frequencies of $30-150 \mathrm{kHz}$. However, ten commonly used $75-\mathrm{kHz}$ pulsed ultrasonic transmitters

\footnotetext{
${ }^{1}$ Present address: Department of Zoology, University of Vermont, Burlington, Vermont 05401.

2 Address reprint requests to J. D. McCleave.
}

(Smith-Root model SR-69 transmitters purchased in 1970) were all audible to us as a faint ticking sound, if the crystal end of the transmitter was placed against the external auditory canal. One Bayshore Systems pressure-sensitive transmitter and one pressure-sensitive transmitter constructed at the University of New Brunswick were also faintly audible. A Smith-Root model SR-69 transmitter purchased in 1975 and one Chipman Instruments transmitter purchased in 1975 were inaudible to us. Though it has been explicitly stated that fish cannot hear continuous wave transmitters (Hawkins et al. 1974), apparently this may not be a valid assumption for pulsed transmitters operating on a short duty cycle. Terhune (1976) measured substantial energy at $1 \mathrm{kHz}$ from a pulsed $200-\mathrm{kHz}$ depth sounder, and discussed that fact in relation to ultrasonic tracking of marine mammals.

This study was undertaken to determine if the output from pulsed transmitters for tracking fish is detectable by Atlantic salmon parr.

\section{METHODS}

Sea-run Atlantic salmon parr (14-25 cm total length) were obtained from Craig Brook National Fish Hatchery, East Orland, Maine. Parr were held at 8-16 C without food for up to two weeks prior to use.

Sensitivity to the transmitter was tested by classical conditioning of cardiac deceleration, with the transmitter output serving as the conditioned stimulus (CS). An AC shock of 1-3 volts across stainless steel plates 30 $\mathrm{cm}$ apart was the unconditioned stimulus (US). The shock level was adjusted for each 
fish to provide distinct cardiac deceleration, but without causing locomotor activity. A slowdown of heartbeat rate for one or two heartbeats following administration of the CS was the conditioned response.

Teflon coated, stainless steel wires $(0.2$ mm diam) served as cardiac electrodes. These were implanted anterior and posterior to the pericardial region as previously described (McCleave et al. 1971). Implantation was performed with the fish anesthetized with either 2-phenoxyethanol $(1: 3,000)$ or tricaine methanesulfonate (1: 1,000). Each fish was placed in a plexiglass aquarium, $100 \mathrm{~cm}$ long $\times 30 \mathrm{~cm}$ wide $\times 37 \mathrm{~cm} \mathrm{deep,} \mathrm{and} \mathrm{restrained} \mathrm{by} \mathrm{a}$ narrow plastic mesh cage $28 \mathrm{~cm}$ long. Water depth in the aquarium was $15-20 \mathrm{~cm}$, and water temperature during experimentation was kept near the temperature at which each fish was held, ranging from 7 to $18 \mathrm{C}$. Each fish was allowed to rest for 1.0 to $1.5 \mathrm{~h}$ before the start of experimentation.

Experiments were conducted with the aquarium in a light-proof insulated chamber. Light was excluded, and sounds and vibrations were dampened.

The transmitter to be used was attached to the underside of the mesh restraining cage in the aquarium. Usually the fish rested on the bottom of the cage, so the transmitter was 2 to $4 \mathrm{~mm}$ below the fish's ventral surface. Transmitters were operated remotely from the recording equipment.

Four groups of experimental fish were used in the study. Eighty training trials were attempted on each fish, and were made on all but six experimental and four control fish. Trials were conducted in sets of ten with 45 min between each set. In the first group ( 12 fish) the intervals between trials were varied between 30 and $90 \mathrm{~s}$, and one of two Smith-Root model SR-69 transmitters (75 kHz, 258 and 194 pulses per min) purchased in 1970 was used. In the second, third, and fourth groups the ten trials came at random times within a 15 -min interval. A Smith-Root model SR-69 transmitter (75 $\mathrm{kHz}, 180$ pulses per min) purchased in 1970 was used with the second group (four fish); a Smith-Root model SR-69 transmitter (75 $\mathrm{kHz}, 200$ pulses per min) purchased in 1975 was used with the third group (seven fish); and a Chipman Instruments transmitter (55 $\mathrm{kHz}, 100$ pulses per min) purchased in 1975 was used with the fourth group (six fish). Each trial consisted of presentation of the CS for the duration of two heartbeats followed by a brief presentation of the US.

Two groups of control fish were used. The first group (seven fish) was treated identically to the first group of experimental fish, except that the transmitter was not connected to a power source. This insured that no artifact of the protocol, such as recording chart drive noise, caused any observed cardiac rate change. In the second control group (seven fish) the presentations of the CS and US were completely randomized (Rescorla 1967) over a 15-min period with each fish receiving ten CS stimuli and ten US stimuli in that period. This random procedure eliminated any contingency whatever between CS and US.

As a check on the effectiveness of cardiac conditioning in Atlantic salmon parr, two additional "control" groups were used. Six fish were given trials in which they were exposed to a distinctly audible $190 \mathrm{~Hz}$ tone from an above-water loudspeaker, but with no US. Six others were given trials with the $190 \mathrm{~Hz}$ tone reinforced by a shock US as in the experimental groups.

Changes in the heartbeat rate were indicated by measurement of the interbeat interval (Rommel and McCleave 1972). The first two beats after the CS was presented were designated the first and second test beats, and the beat just prior to the CS was designated the test reference beat. The percent change in rate from the reference beat to each test beat was calculated. Prior to the test reference beat in each trial, a control reference beat and two control beats were recorded. Similar calculations with these three beats indicated any change in heart rate when neither the CS nor the US was present.

For each group of fish the mean percent change in each of the two test beats was calculated for each trial from 1 to 80 . For each test beat the cumulative percent change at each of the 80 trials was plotted against trial number. The resulting graphs were used to compare groups. A one-tailed 

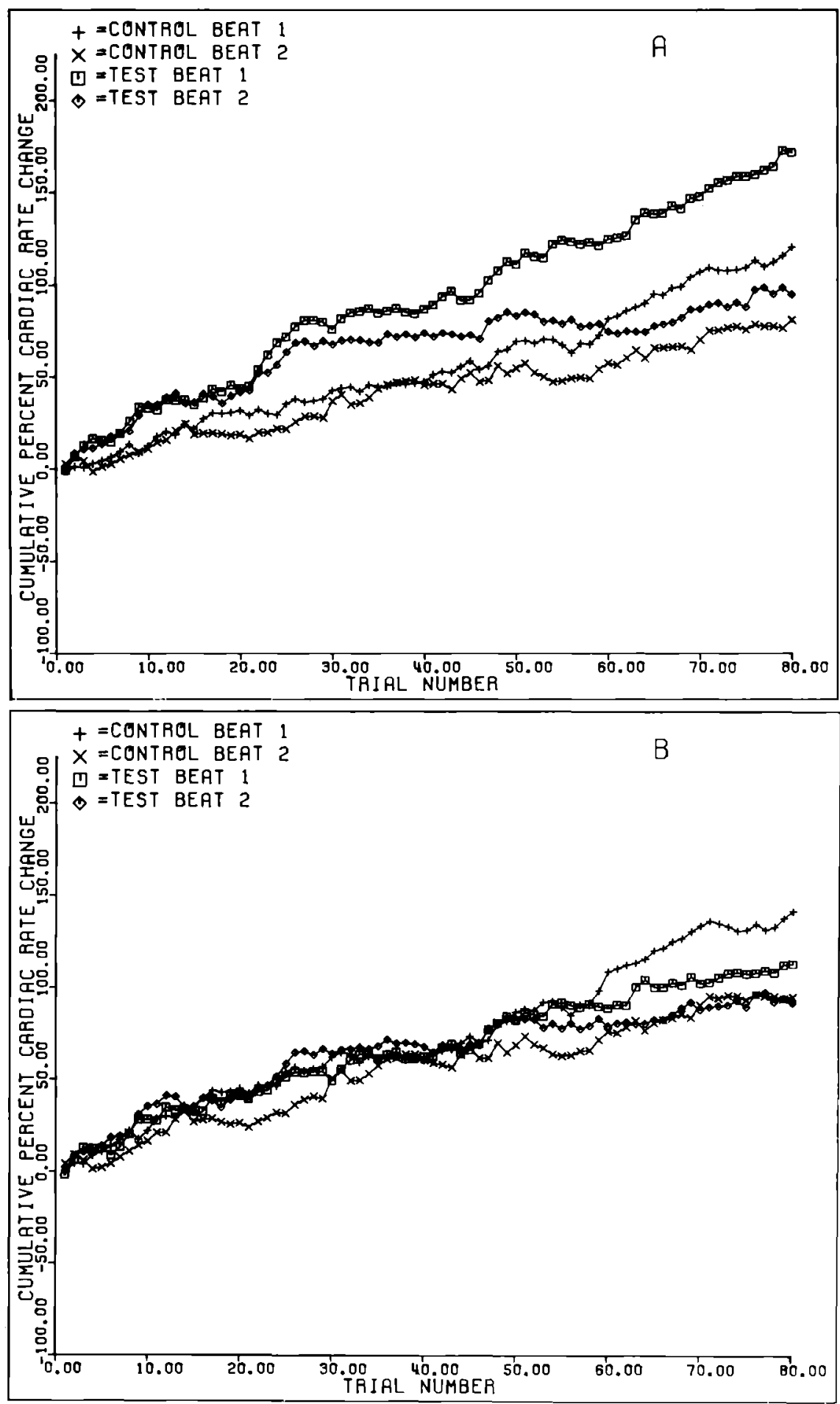

FIGURE 1.-Cumulative percent change in cardiac rate over 80 trials of Atlantic salmon parr for (A) 29 experimental fish in response to ultrasonic transmitter output, and $(B) 25$ experimental fish not conditioned. Each point is the cumulative mean percent change for all salmon in the group. 
TABLE 1.-Responses of Atlantic salmon parr to output of ultrasonic transmitters. (Significance criterion is one-tailed Wilcoxon's signed ranks test between percent change in test beat median and control beat median at $95 \%\left(^{*}\right)$ and $99 \%\left(^{* *}\right)$ level.)

\begin{tabular}{|c|c|c|c|c|}
\hline $\begin{array}{l}\text { Number of } \\
\text { trials }\end{array}$ & $\begin{array}{l}\text { Percent change in } \\
\text { first control beat } \\
\text { (Mean } \pm \text { SD) }\end{array}$ & $\begin{array}{l}\text { Percent change in } \\
\text { first test beat } \\
\text { (Mean } \pm \text { SD) }\end{array}$ & $\begin{array}{l}\text { Percent change in } \\
\text { second control beat } \\
\text { (Mean } \pm \text { SD) }\end{array}$ & $\begin{array}{l}\text { Percent change in } \\
\text { second test beat } \\
\text { (Mean } \pm \mathrm{SD} \text { ) }\end{array}$ \\
\hline \multicolumn{5}{|c|}{ Experimental Group I: 1970 Smith-Root Model SR-69 } \\
\hline $\begin{array}{l}79 \\
70 \\
79 \\
80 \\
80 \\
72 \\
80 \\
80 \\
80 \\
80 \\
80 \\
80\end{array}$ & $\begin{aligned} 3.2 & \pm 25.4 \\
-0.1 & \pm 4.5 \\
-0.6 & \pm 22.4 \\
1.4 & \pm 11.5 \\
0.8 & \pm 9.1 \\
-1.4 & \pm 19.9 \\
5.7 & \pm 25.9 \\
1.3 & \pm 8.9 \\
-0.6 & \pm 6.2 \\
0.4 & \pm 7.5 \\
-0.7 & \pm 5.6 \\
-0.1 & \pm 24.1\end{aligned}$ & $\begin{aligned} 3.1 & \pm 26.8 \\
0.3 & \pm 4.9 \\
7.4 & \pm 28.7^{*} \\
14.9 & \pm 34.7^{*} \\
-0.6 & \pm 11.8 \\
1.5 & \pm 22.2 \\
-1.2 & \pm 21.0 \\
0.1 & \pm 12.8 \\
1.2 & \pm 6.8 \\
-0.5 & \pm 5.0 \\
0.5 & \pm 5.8^{*} \\
5.8 & \pm 33.6\end{aligned}$ & $\begin{aligned}-1.3 & \pm 21.8 \\
-0.3 & \pm 5.0 \\
-2.3 & \pm 22.5 \\
1.2 & \pm 13.8 \\
0.6 & \pm 11.2 \\
-1.1 & \pm 19.5 \\
2.6 & \pm 16.2 \\
0.9 & \pm 10.2 \\
0.7 & \pm 13.6 \\
-0.9 & \pm 6.6 \\
-0.4 & \pm 4.5 \\
2.9 & \pm 25.2\end{aligned}$ & $\begin{aligned} 3.6 & \pm 22.8 \\
-0.1 & \pm 7.1 \\
-1.5 & \pm 24.1 \\
3.1 & \pm 19.7 \\
1.7 & \pm 15.6 \\
-0.1 & \pm 20.3 \\
-1.3 & \pm 21.2 \\
-0.4 & \pm 11.1 \\
0.6 & \pm 9.8 \\
-1.3 & \pm \mathbf{5 . 1} \\
1.1 & \pm 7.9^{*} \\
7.6 & \pm 36.6\end{aligned}$ \\
\hline \multicolumn{5}{|c|}{ Experimental Group 2: 1970 Smith-Root Model SR-69 } \\
\hline $\begin{array}{l}80 \\
80 \\
80 \\
80\end{array}$ & $\begin{array}{r}0.6 \pm 6.4 \\
0.6 \pm 11.7 \\
4.1 \pm 23.3 \\
-0.6 \pm 16.6\end{array}$ & $\begin{array}{l}1.0 \pm 8.5 \\
3.0 \pm 18.8 \\
8.2 \pm 36.8 \\
1.5 \pm 19.1\end{array}$ & $\begin{array}{r}1.7 \pm 10.4 \\
-1.8 \pm 16.8 \\
-0.7 \pm 19.9 \\
0.1 \pm 18.8\end{array}$ & $\begin{array}{r}3.3 \pm 10.8 \\
-2.2 \pm 14.2 \\
5.3 \pm 27.1 \\
1.3 \pm 19.6\end{array}$ \\
\hline \multicolumn{5}{|c|}{ Experimental Group 3: 1975 Smith-Root Model SR-69 } \\
\hline $\begin{array}{l}79 \\
78 \\
80 \\
80 \\
80 \\
80 \\
80\end{array}$ & $\begin{aligned} 1.1 & \pm 11.9 \\
0.0 & \pm 2.0 \\
-0.3 & \pm 1.6 \\
5.1 & \pm 17.4 \\
1.7 & \pm 14.0 \\
4.9 & \pm 14.6 \\
0.1 & \pm 14.9\end{aligned}$ & $\begin{array}{r}0.3 \pm 3.4 \\
0.1 \pm 2.0 \\
0.1 \pm 1.5 \\
2.5 \pm 16.8 \\
0.3 \pm 16.6 \\
-0.9 \pm 11.6 \\
-0.3 \pm 16.7\end{array}$ & $\begin{array}{r}-0.3 \pm 4.1 \\
-0.5 \pm 1.8 \\
-0.1 \pm 1.8 \\
4.5 \pm 18.8 \\
4.1 \pm 19.7 \\
3.6 \pm 10.7 \\
1.2 \pm 18.9\end{array}$ & $\begin{aligned} 0.5 & \pm 5.4 \\
0.1 & \pm 2.2 \\
0.3 & \pm 2.7 \\
0.1 & \pm 16.4 \\
-1.2 & \pm 11.8 \\
2.2 & \pm 11.9 \\
-0.9 & \pm 20.5\end{aligned}$ \\
\hline \multicolumn{5}{|c|}{ Experimental Group 4: 1975 Chipman Instruments } \\
\hline $\begin{array}{l}80 \\
80 \\
80 \\
80 \\
80 \\
80\end{array}$ & $\begin{aligned} 9.3 & \pm 34.4 \\
0.3 & \pm 5.5 \\
3.7 & \pm 21.5 \\
-1.6 & \pm 8.7 \\
0.5 & \pm 5.2 \\
3.8 & \pm 22.4\end{aligned}$ & $\begin{aligned} 2.8 & \pm 25.0 \\
0.4 & \pm 4.4 \\
3.2 & \pm 21.0 \\
4.2 & \pm 23.8^{* *} \\
-0.3 & \pm 6.9 \\
2.3 & \pm 22.7\end{aligned}$ & $\begin{array}{l}6.5 \pm 25.6 \\
0.0 \pm 6.5 \\
6.3 \pm 20.1 \\
0.6 \pm 13.1 \\
0.2 \pm 3.7 \\
0.7 \pm 18.2\end{array}$ & $\begin{aligned} 3.4 & \pm 25.0 \\
0.9 & \pm 7.4 \\
5.3 & \pm 22.7 \\
2.6 & \pm 16.5 \\
1.0 & \pm 7.4 \\
-0.6 & \pm 17.7\end{aligned}$ \\
\hline \multicolumn{5}{|c|}{ Control Group I: 1970 Smith-Root Model SR-69 } \\
\hline $\begin{array}{l}80 \\
80 \\
80 \\
80 \\
80 \\
80 \\
80\end{array}$ & $\begin{aligned} 2.2 & \pm 10.3 \\
0.8 & \pm 19.3 \\
3.0 & \pm 14.6 \\
0.0 & \pm 3.4 \\
-1.1 & \pm 9.7 \\
2.3 & \pm 12.9 \\
-0.7 & \pm 7.2\end{aligned}$ & $\begin{aligned}-0.3 & \pm 11.7 \\
-0.1 & \pm 19.2 \\
3.6 & \pm 15.6 \\
-0.3 & \pm 4.6 \\
-1.1 & \pm 10.2 \\
-0.1 & \pm 12.0 \\
-0.7 & \pm 8.0\end{aligned}$ & $\begin{aligned}-0.6 & \pm 15.2 \\
0.5 & \pm 18.7 \\
3.6 & \pm 16.6 \\
0.1 & \pm 4.0 \\
-1.3 & \pm 10.7 \\
0.0 & \pm 12.2 \\
-0.9 & \pm 8.6\end{aligned}$ & $\begin{aligned} 1.2 & \pm 16.8 \\
-0.9 & \pm 18.5 \\
5.0 & \pm 22.0 \\
0.8 & \pm 6.6 \\
-1.8 & \pm 11.7 \\
-2.5 & \pm 11.4 \\
-0.3 & \pm 8.3\end{aligned}$ \\
\hline \multicolumn{5}{|c|}{ Control Group 2: 1975 Smith-Root Model SR-69 and 1975 Chipman Instruments } \\
\hline $\begin{array}{l}67 \\
80 \\
79 \\
70 \\
79 \\
80 \\
80\end{array}$ & $\begin{aligned} &-0.4 \pm 12.8 \\
&-1.7 \pm 6.3 \\
& 4.6 \pm 24.2 \\
& 0.4 \pm 11.8 \\
&-1.0 \pm 22.1 \\
& 2.2 \pm 28.1 \\
& 12.2 \pm 33.9\end{aligned}$ & $\begin{aligned}-1.7 & \pm 9.1 \\
0.1 & \pm 7.5^{*} \\
0.7 & \pm 16.7 \\
-0.2 & \pm 6.3 \\
-1.6 & \pm 24.0 \\
3.0 & \pm 20.8 \\
3.7 & \pm 31.4\end{aligned}$ & $\begin{array}{r}-1.7 \pm 10.9 \\
-0.4 \pm 13.7 \\
0.2 \pm 17.1 \\
-0.3 \pm 10.5 \\
-6.1 \pm 23.5 \\
-0.4 \pm 26.4 \\
2.0 \pm 18.5\end{array}$ & $\begin{aligned}-0.3 & \pm 11.1 \\
-0.1 & \pm 7.3 \\
1.9 & \pm 22.1 \\
-0.3 & \pm 6.8 \\
3.8 & \pm 24.5 * * \\
2.8 & \pm 23.7 \\
0.8 & \pm 22.2\end{aligned}$ \\
\hline \multicolumn{5}{|c|}{ "Control" Group 3: $190 \mathrm{~Hz}$ tone, without US } \\
\hline $\begin{array}{l}70 \\
80 \\
69 \\
80 \\
80 \\
80\end{array}$ & $\begin{array}{l}0.8 \pm 3.6 \\
3.2 \pm 15.0 \\
1.0 \pm 20.0 \\
0.4 \pm 3.0 \\
0.2 \pm 3.9 \\
-0.1 \pm 8.0\end{array}$ & $\begin{aligned} &-0.1 \pm 2.6 \\
& 2.2 \pm 16.3 \\
& 8.5 \pm 23.8^{*} \\
& 1.2 \pm 2.7 \\
& 0.6 \pm 4.9 \\
& 2.9 \pm 9.8^{* *}\end{aligned}$ & $\begin{aligned} 0.7 \pm 2.8 \\
1.6 \pm 16.7 \\
2.5 \pm 21.7 \\
0.6 \pm 2.8 \\
0.2 \pm 4.2 \\
-0.2 \pm 10.0\end{aligned}$ & $\begin{array}{l}0.2 \pm 2.2 \\
2.6 \pm 19.0 \\
8.6 \pm 21.6 \\
0.6 \pm 2.8 \\
0.5 \pm 5.3 \\
0.9 \pm 10.3\end{array}$ \\
\hline \multicolumn{5}{|c|}{ "Control" Group 4: $190 \mathrm{~Hz}$ tone as CS, with US } \\
\hline $\begin{array}{l}80 \\
80 \\
65 \\
80 \\
80 \\
80\end{array}$ & $\begin{aligned} 0.0 & \pm 13.5 \\
0.3 & \pm 9.3 \\
0.3 & \pm 3.0 \\
1.3 & \pm 14.3 \\
0.5 & \pm 10.4 \\
-1.3 & \pm 16.9\end{aligned}$ & $\begin{aligned} 1.5 & \pm 12.5 \\
11.8 & \pm 38.5^{* *} \\
2.7 & \pm 13.3 \\
3.0 & \pm 12.2 \\
12.9 & \pm 19.3^{* *} \\
5.6 & \pm 17.8^{* *}\end{aligned}$ & $\begin{array}{r}-0.3 \pm 11.8 \\
2.1 \pm 16.9 \\
0.8 \pm 3.8 \\
0.6 \pm 9.7 \\
0.4 \pm 11.1 \\
-3.2 \pm 13.4\end{array}$ & $\begin{aligned} 4.0 & \pm 14.0^{*} \\
34.9 & \pm 59.3^{* *} \\
7.7 & \pm 17.2^{* *} \\
23.4 & \pm 37.9^{* *} \\
39.1 & \pm 40.4^{* *} \\
16.2 & \pm 37.1^{* *}\end{aligned}$ \\
\hline
\end{tabular}




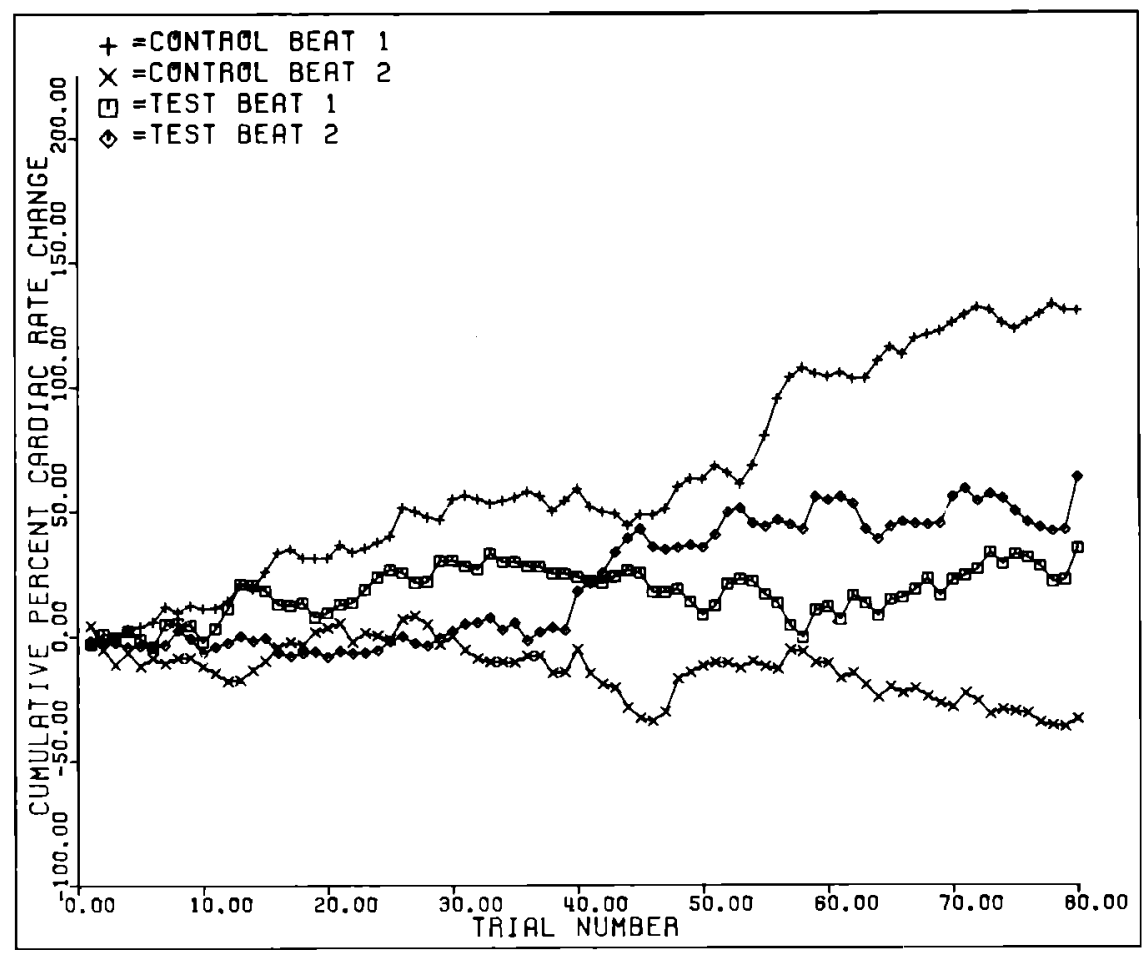

FIGURE 2.-Cumulative mean percent change in cardiac rate over 80 trials of 14 control Atlantic salmon parr.

Wilcoxon's signed ranks test was used to compare the interbeat intervals of corresponding test beats and control beats over the 80 trials, and if test medians for either test beat one or test beat two were significantly greater than control medians, the conclusion was that conditioning had occurred (Rommel and McCleave 1973). Means and standard deviations are presented to provide a measure of variability in the data, but the non-parametric Wilcoxon's test is used since the data are not normally distributed and the 80 trials are not independent of one another.

\section{RESULTS}

The results give little reason to believe that the Atlantic salmon parr tested were capable of hearing the modern ultrasonic transmitters used. By our criterion four of the 29 experimental fish showed a significant cardiac deceleration over the course of 80 test trials (Table 1). Three of these four fish were from a group of 16 tested with older Smith-Root transmitters. The fourth was one of a group of six tested with a new Chipman transmitter. Of seven fish tested with a new Smith-Root transmitter none showed any significant cardiac deceleration. A plot of cumulative percent cardiac rate change over the 80 test trials for all 29 experimental fish shows a slight increase in test beat one (Fig. 1A). However, this is caused by the influence of the rate changes of the four significant fish on the remainder of the group, as can be seen in a plot without these four fish (Fig. 1B).

Two of 14 control fish also showed significant deceleration in heart rate upon presentation of the CS (Table 1). These two controls were in the randomized group (seven fish) in which the CS and US were presented in random order to eliminate any contingency between them. A plot of cumulative percent cardiac rate change over 80 trails shows no change in either test beats one or two (Fig. 2). The equal percentage of "significant" experimentals and con- 

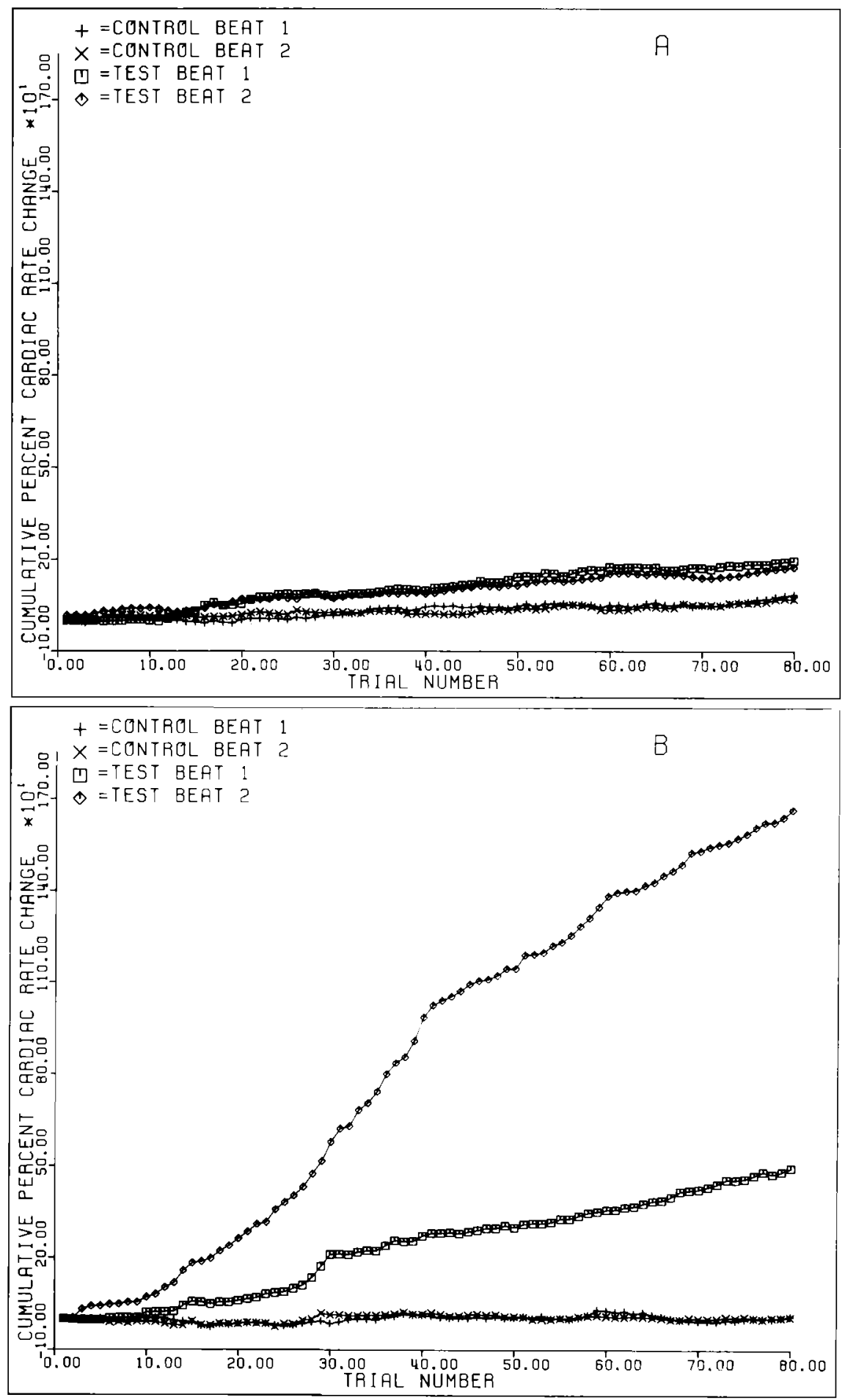

FIGURE 3.-Cumulative mean percent change in cardiac rate over 80 trials of Atlantic salmon parr for (A) six "control" fish in response to $190 \mathrm{~Hz}$ tone without unconditioned stimulus (US), and (B) six "control" fish in response to $190 \mathrm{~Hz}$ tone with a shock US. (Note scale of ordinate is $\times 10^{1}$.) 
trols $(14 \%)$ allows no reasonable argument that the fish tested could actually hear the transmitters.

Conditioned cardiac deceleration is a highly effective technique for use with Atlantic salmon parr, however, as indicated by the large conditioned responses to a $190 \mathrm{~Hz}$ tone (Table 1, Fig. 3).

\section{DISCUSSION}

The prior use of classically conditioned cardiac deceleration in fish sensory physiology studies, plus our own success at conditioning salmon parr to a $190 \mathrm{~Hz}$ tone, leads us to believe that the low number of conditioned responses in the present study was not due to any procedural flaw, but means rather that the fish were not capable of detecting the CS. This phenomenon of classically conditioned cardiac deceleration was first demonstrated in goldfish (Carassius auratus) by Otis et al. (1957). They monitored heart rate and respiratory movements and successfully conditioned the goldfish using a flash of light as the CS and an electric shock as the US. Auditory thresholds in goldfish and tautog (Tautoga onitis) were determined by Offutt $(1968,1971)$.

The results of this study strongly suggest that the output of modern pulsed ultrasonic transmitters is not detectable by Atlantic salmon parr, although it is remotely possible that internally placed transmitters could have been detected. McCleave and Stred (1975) found that internally placed dummy transmitters, the size of Chipman transmitters, caused no significant decrement in swimming performance of Atlantic salmon smolts. Fried et al. (1976) found that Atlantic salmon smolts tagged internally with dummy transmitters and given access to the water surface gradually regained most of their initial buoyancy over a 6 -h test period, while tagged fish without access to the surface never regained buoyancy.

Gallepp and Magnuson (1972) showed that bluegills were capable of compensating for about two-thirds of the excess mass of an internal weight ( $2.75 \mathrm{~g}$ in water) in $3 \mathrm{~h}$, although they still did not fully compensate in 5 h. External placement of small sonic tags on brown trout (Salmo trutta) had no observed effect on behavior patterns (Young et al. 1972). Shepherd (unpublished) found no behavioral differences between externally tagged and untagged hatchery rainbow trout (Salmo gairdneri) tested in the laboratory, but he did find decreased levels of activity of wild cutthroat trout (Salmo clarki) tagged externally and tracked in the field.

These studies all supply necessary information regarding the effects of telemetric devices on fishes. More research, particularly with respect to the effects of stomach tag placement on feeding, should be done before any long-term tracking studies are undertaken.

\section{ACKNOWLEDGMENTS}

We thank Dr. George W. LaBar for assistance, and Dr. Sentiel A. Rommel, Jr., for review of the manuscript. Funds were provided by the U.S. Fish and Wildlife Service contracts 14-16-0008-773 and 14-16-0008893 with James D. McCleave.

\section{LITERATURE CITED}

Donson, J. J., W. C. Leggett, And R. A. Jones. 1972. The behavior of adult American shad (Alosa sapidissima) during migration from salt to fresh water as observed by ultrasonic tracking techniques. J. Fish. Res. Board Can. 29(10):1445-1449.

Ferrel, D. W., D. R. Nelson, T. C. Scariotta, E. H. Standora, AND H. C. Carter. 1973. A multichannel ultrasonic marine bio-telemetry system for monitoring marine animal behavior at sea. Instrum. Aerosp. Ind. 19:71-84.

Frted, S. M., J. D. MCCleave, and K, A. Stred. 1976. Buoyancy compensation by Atlantic salmon (Salmo salar) smoits tagged internally with dummy telemetry transmitters. J. Fish. Res. Board Can. 33(6):1377-1380.

GallePP, G. W., AND J. J. Magnuson. 1972. Effects of negative buoyancy on the behavior of the bluegill, Lepomis macrochirus Rafinesque. Trans. Am. Fish. Soc. 101(3):507-512.

Greer Walker, M., R. B. Mitson, AND T STORETON-WEst. 1971. Trials with a transponding acoustic fish tag tracked with an electronic sector scanning sonar. Nature 229(5281):196-198.

Hawkıns, A. D., D. N. MacLennan, G. G. URQUHART, AND C. RoBB. 1974. Tracking cod Gadus morhua L. in a Scottish sea loch. J. Fish Biol. 6(3):225-236.

Henderson, H. F. A. D. Hasler, and G. C. ChipMAN. 1966. An ultrasonic transmitter for use in studies of movements of fishes. Trans. Am. Fish. Soc. 95(4):350-356.

Johnson, J. H. 1963. Development and use of sonic tracking as an aid to Pacific salmon conservation studies. U.S. Bur. Comm. Fish., mimeo rep. 14 pp. Unpublished.

Luke, D. M., D. G. Pincock, and A. B. Stasko. 
1973. Pressure-sensing ultrasonic transmitter for tracking aquatic animals. J. Fish. Res. Board Can. 30(9): 1402-1404.

Madison, D. M., R. M. Horrall, A. B. Stasko, And A. D. HASLER. 1972. Migratory movements of adult sockeye salmon (Oncorhynchus nerka) in coastal British Columbia as revealed by ultrasonic tracking. J. Fish. Res. Board Can. 29(7):10251033.

McCleave, J. D., and G. W. LaBar. 1972. Further ultrasonic tracking and tagging studies of homing cut throat trout (Salmo clarki) in Yellowstone Lake. Trans. Am. Fish. Soc. 101(1):44-54.

- , S. A. Rommel, JR., and C. L. Cathcart. 1971. Weak electric and magnetic fields in fish orientation. Ann. N.Y. Acad. Sci. 188:270-282.

- AND K. A. STRED. 1975. Effect of dummy telemetry transmitters on stamina of Atlantic salmon (Salmo salar) smolts. J. Fish. Res. Board Can. 32(4):559-563.

OFFuTT, G. C. 1968. Auditory response in the goldfish. J. Aud. Res. 8(4):391-400.

1971. Response of the tautog (Tautoga onitis, Teleost) to acoustic stimuli as measured by classically conditioning the heart rate. Cond. Reflex 6(4):205-214.

Otis, L. S., J. A. Cerf, and J. Thomas. 1957. Conditioned inhibition of respiration and heart rate in the goldfish. Science 126(3267):263-264.
Rescorla, R. A. 1967. Pavlovian conditioning and its proper control procedures. Psychol. Rev. $74(1): 71-80$.

Rommel, S. A., JR., And J. D. McCleave. 1972. Oceanic electric fields: perception by American eels? Science 176(4040): 1233-1235.

—— AND - 1973. Sensitivity of American eels (Anguilla rostrata) and Atlantic salmon (Salmo salar) to weak electric and magnetic fields. J. Fish. Res. Board Can. 30(5):657-663.

Stasko, A. B., R. M. Horrall, A. D. Hasler, AND D. STASKo. 1973. Coastal movements of mature Fraser River pink salmon (Oncorhyncus gorbuscha) as revealed by ultrasonic tracking. J. Fish. Res. Board Can. 30(9): 1309-1316.

Tavolga, W. N. 1971. Sound production and detection. Pages 135-205 in W. S. Hoar and D. J. Randall, eds. Fish physiology. Vol. V. Academic Press, New York.

Terhune, J. M. 1976. Audibility aspects of sonic tracking of marine mammals. J. Mammal. 57:179-180.

Thefethen, P. S. 1956. Sonic equipment for tracking individual fish. U.S. Fish Wild. Serv., Spec. Sei. Rep. Fish. 179:1-11.

Young, A. H., P. Tytler, F. G. T. Holliday, and A. MacFARLANe. 1972. A small sonic tag for measurement of locomotory behaviour in fish. J. Fish Biol. 4(1):57-65. 